Vol 13, Issue 9, 2020

\title{
CORONAVIRUS DISEASE 2019, DENGUE HEMORRHAGIC FEVER, AND THE CLINICAL SIMILARITY
}

\section{KETUT SURYANA*}

Department of Internal Medicine at Wangaya Hospital in Denpasar, Bali, Indonesia. Email: ketutsuryana@gmail.com

Received: 16 May 2020, Revised and Accepted: 20 June 2020

\begin{abstract}
Recently, coronavirus disease-19 (COVID-19) case is increasing in Indonesia, simultaneously with the outbreak of dengue hemorrhagic fever (DHF). DHF is generally observed to rise at the beginning of the year that peaks between March and April due to the rainy season and high temperatures. The outbreak of COVID-19 started in Wuhan, China, since December 2019, and it has spread quickly worldwide as a pandemic. COVID-19 and DHF have had comparable clinical indication, laboratory highlights, and it has serious implications for the patients as well as for the general health. Therefore, to distinguish, all the doctors in the primary health care have to be aware and to work carefully.
\end{abstract}

Keywords: Coronavirus disease-19, Dengue hemorrhagic fever, Clinical similarity.

(C) 2020 The Authors. Published by Innovare Academic Sciences Pvt Ltd. This is an open access article under the CC BY license (http://creativecommons. org/licenses/by/4. 0/) DOI: http://dx.doi.org/10.22159/ajpcr.2020.v13i9.38454

\section{INTRODUCTION}

The coronavirus (CoV) disease (COVID-19) has constituted a global health problem and as the international concern, with cases confirmed in multiple areas or countries [1,2]. The World Health Organization (WHO) has declared the COVID-19 as a global pandemic. COVID-19 is an acute infectious respiratory disease which is a novel CoV as a causative agent. The COVID-19 incubation period is about 2-14 days, and the main routes of transmission are considered through respiratory droplets and close person-to-person contact (within $1 \mathrm{~m}$ ). Transmission can likewise occur if an individual contacts a surface or objects might be a pet that has the infection on it and afterward contacts their own mouth, nose, or their eyes [3-5]. The disease reported has ranged from asymptomatic, mild-to-severe clinical manifestation, and eventually to death $[6,7]$. The most frequent symptoms include fever, cough, shortness of breath, pneumonia, and other respiratory tract abnormalities [8-10]. The diagnosis of COVID-19 is affirmed by reverse transcription-polymerase chain reaction (RT-PCR) test from pharyngeal swab tests and lesions identification by chest X-ray [11-13]. The COVID-19 has no specific treatment, antibiotic, and antiviral therapies; also, other supportive cares are recommended [14].

Dengue hemorrhagic fever (DHF) caused by dengue virus (DENV) has been considered as the arboviral infection. The clinical manifestations of DHF such as fever or history of intense fever, enduring 2-7 days, sometimes biphasic. Hemorrhagic propensities confirm by in any event one of the accompanying: Petechiae, a positive tourniquet test, purpura, ecchymoses, infusion destinations, or different areas, for example, hematemesis or melena, bleeding from the mucosa, gastrointestinal tract, and thrombocytopenia $\left(\leq 150.000\right.$ cells per $\left.\mathrm{mm}^{3}\right)$. Evidence of plasma leakage due to expanded vascular permeability is an increase in hematocrit (Hct) levels by $5-10 \%$. The diagnosis for DHF, clinically are high fever of acute onset, hemorrhagic manifestation at least a positive tourniquet test, hepatomegaly, and shock. The laboratory results support clinical observations [15-17].

We report a case of a male 30 years old, who previously was diagnosed as DHF but finally confirmed to be COVID-19. The patient specifically provided written informed consent to participate in this study. The study procedure has approved by the Ethical Committee of Wangaya Hospital in Denpasar Bali Indonesia with register number: 02/RSUDW/ Litbang/2020 and allowed to publish this study.

\section{CASE REPORT}

A male 30 years old, who came to emergency unit at Wangaya hospital in Denpasar, Bali, Indonesia, on April 5, 2020, reported with a chief complaint fever (acute febrile illness) for 7 days prior admission. Medical history; he was also with headache and unclear past medical, travel, or contact history (due to the possibility of COVID-19). The patient was fever (high temperature $39.2^{\circ} \mathrm{C}$ ), blood pressure $100 / 70 \mathrm{mmHg}$, pulse rate $104 \mathrm{x} / \mathrm{min}$ regularly, respiratory rate $26 \mathrm{x} / \mathrm{min}$, and fully alert. He had thrombocytopenia: Platelet count $130 \times 10^{3} / \mu \mathrm{L}\left(150-450.10^{3} / \mathrm{mm}^{3}\right)$, high hemoglobin level $17.2 \mathrm{~g} / \mathrm{dL}$ (13.0-16.0 g/dL), Hct 51.6\% (40.0-48.0\%), normal of lymphocyte, and neutrophil levels. The working diagnosis was DHF and given the symptomatically therapy, high calories, high protein diet, and intravenous fluid drip.

On the $4^{\text {th }}$ day admission (April 8, 2020), he complained of cough. Thrombocytopenia (platelet $146 \times 10^{3} / \mu \mathrm{L}$ ) and the chest X-ray showed the minimal infiltrate and was concluded pneumonia. The chest X-ray leads to a test for anti-severe acute respiratory syndrome (SARS)-CoV-2 and continued with SARS-CoV-2 by RT-PCR from a nasopharyngeal swab. The results; anti-SARS-CoV-2 was reactive (Rapid test) and SARS-CoV-2 was positive (RT-PCR). He was confirmed with pneumonia caused by CoV (COVID-19), as described in Fig. 1.

The patient was isolated and treated with antiviral drug (75 mg oseltamivir twice daily), antibiotics (500 mg azithromycin once daily), $400 \mathrm{mg}$ hydroxychloroquine once daily, $600 \mathrm{mg}$ ascorbic acid iv, and $2 \mathrm{~L} / \mathrm{min}$ oxygen intravenous fluid drip $(\mathrm{NaCl} 0.9 \%)$. At the $8^{\text {th }}$ day admission, he was getting better (the temperature of the patient to be normal and the symptoms disappeared).

The schematic of the case progress note.

\section{DISCUSSION}

COVID-19 and DHF are frequently difficult to recognize due to the fact that they have had comparable clinical manifestation and laboratory features. Both COVID-19 and DHF are caused by virus; COVID-19 is caused by CoV and DHF is caused by DENV. The clinical presentation of both diseases ranges from asymptomatic to serious disease and eventually leads to death. The clinical manifestation similarity of both COVID-19 and DHF is fever, headache, cough with thrombocytopenia, 


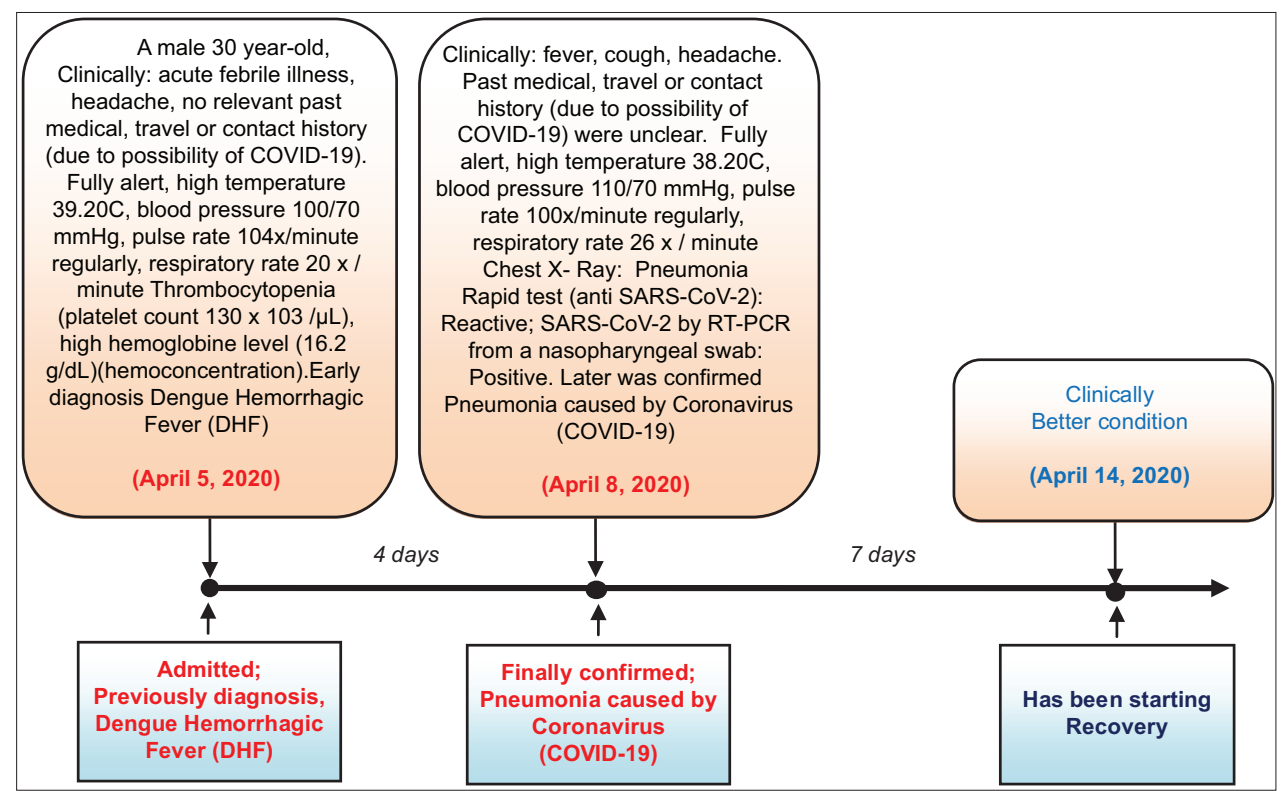

Fig. 1: The schematic of case progress note

and leukopenia [8-10,15-17]. The comparison of COVID-19 and DHF as described in Table 1.

Further, epidemiological study about travel and contact history that gained from detailed anamnesis and massive screening (Rapid test and RT-PCR) is essential to distinguish between COVID-19 and DHF. COVID-19 is a novel virus, there are still a stigma and fear about suffering from this virus. Patients tend to dissemble their history that it often leads to misdiagnosed. Furthermore, asymptomatic patients feel healthy still on their routine activity without knowing that they possibly spread the virus. DHF transmission through the bite of Aedes sp. mosquitoes infected with Dengue virus. COVID-19 transmission is considered by means of respiratory droplets and close human to human contact (inside 1 meter). Transmission, perhaps at the same time, happens if a human contacts a surface or object might be pet that has the infection on it and afterward contacts their own mouth, nose, or their eyes [8-10,15-17]

As indicated by the WHO 2011, dengue disease is suspected in patient with high fever (intense febrile sickness) and the accompanying signs or symptoms: Cerebral pain, rash, retro-orbital torment, myalgia, arthralgia/ bone agony, positive tourniquet test or draining appearance, for example, petechiae, epistaxis, gum bleeding, hematemesis, and melena. Leukopenia can be defined as a condition where white blood cell $\leq 5000$ cells $/ \mathrm{mm}^{3}$, platelet count $\leq 150,000$ cells $/ \mathrm{mm}^{3}$, hematocrit (Hct) increasing $5-10 \%$ $[16,17]$. In this patient, we found high fever, thrombocytopenia, and Hct rising $7.5 \%$ (5-10\%), the working diagnosis was DHF.

The diagnosis of COVID-19 can be founded on a combination of epidemiologic data, for example, a background marked by movement to or living arrangement in influenced area 14 days preceding symptoms beginning, clinical symptoms, and chest X-ray, CT imaging finding is more sensitive and specific, laboratory test, and RT-PCR tests on respiratory tract specimens according to the WHO standards [1,2]. In this patient, we found that the medical history, travel, or contact history (due to the possibility of COVID-19) was unclear. He complained cough and thrombocytopenia (platelet $146 \times 10^{3} / \mu \mathrm{L}$ ) and the chest X-ray showed the minimal infiltrate, and it was concluded pneumonia. The chest X-ray leads to a test for anti-SARS-CoV-2 and continued with SARS-CoV-2 by RT-PCR from a nasopharyngeal swab. The results; antiSARS-CoV- 2 was reactive (Rapid test) and SARS-CoV-2 was positive (RTPCR). He was confirmed with pneumonia caused by CoV (COVID-19)

We would like to share our experience with Wangaya Hospital in Denpasar, Bali, Indonesia. There is an interesting case, in which the
Table 1: Comparison of COVID-19 and DHF

\begin{tabular}{lll}
\hline Finding & COVID-19 & DHF \\
\hline Fever & +++ & +++ \\
Headache & ++ & ++ \\
Cough & ++ & \pm \\
Thrombocytopenia & + & + \\
Leukopenia & + & + \\
\hline
\end{tabular}

COVID: Coronavirus disease, DHF: Dengue hemorrhagic fever

patient presented with a fever (acute febrile illness). Because we are facing the dengue outbreak, and the patient also had low platelet count and from the history taking, no applicable past clinical, travel, or contact history due to the possibility of COVID-19. A clinical diagnose of dengue was made for the $1^{\text {st }}$ day of admission. In the next day of admission, the patient presented respiratory problems (cough) and he was confirmed pneumonia by chest X-ray examination. Based on the prior examination, a laboratory examination rapid test and RT-PCR were made; then, the patient was confirmed with pneumonia caused by COVID-19.

There is a possibility that from anamnesis, a patient with COVID-19 has unclear past medical, travel, or contact history, it often leads to misdiagnosed. Therefore, a detailed anamnesis and completed by hetero-anamnesis, including the environment and the detailed contacts (mobility and person-to-person contact) and a massive screening are needed.

\section{CONCLUSION}

We reported a case, a male 30 years old, with unclear medical, travel, or contact history due to the possibility of COVID-19. He admitted to Wangaya hospital, with 7 days of the history of fever, headache, and thrombocytopenia. The patient was previously concluded as DHF. On the $4^{\text {th }}$ day hospitalized, he complained cough and chest X-ray showed pneumonia, RT-PCR of the nasopharyngeal swab was positive, therefore finally, he was confirmed with COVID-19.

\section{ACKNOWLEDGMENTS}

The author would like to thank the patient and his family for the cooperation and also to thank Wayan Wahyu Semara Putra (Pulmonologist), Ni Made Dwita Yaniswari (Pulmonologist) and Ida Ayu Ngurah Artayati, Wayan Ernawati, Ketut Ayu Sugiantari, and all the team members who support during preparing this case report. 


\section{AUTHORS' CONTRIBUTION}

Ketut Suryana made a substantial contribution in conception, acquisition of data, interpretation of data, in drafting the article and revising it for ensuring critical academic content; gave final approval of the version to be published; and agreed to be held accountable for all aspects of the work.

\section{CONFLICT OF INTEREST}

The authors declared that there is no conflict of interest related to this study.

\section{AUTHOR'S FUNDING}

The author(s) received no specific funding for this work.

\section{REFERENCES}

1. Meng L, Hua F, Bian Z. Coronavirus disease 2019 (COVID-19) emerging and future challenges for dental and oral medicine. J Dent Res 2020;99:481-7.

2. Singhai T. A review of coronavirus disease-2019 (COVID-19). Indian J Pediatr 2020;87:281-6.

3. Kolifarhood G, Aghaali M, Saadati HM, Taherpour N, Rahimi S, Izadi N, et al. Epidemiological and clinical aspects of COVID-19; a narrative review. Arch Acad Emerg Med 2020;8:e41.

4. Abdulamir AS, Hafids RR. The possible immunological pathways for the variable immunopathogenesis of COVID-19 infection among healthy adults, elderly and children. Electron J Gen Med 2020;17:1-4.

5. Yi Y, Lagniton PN, Ye S, Li E, Xu RH. CVOID-19: What has been learned and to be learned about the novel coronavirus disease. Int J Biol Sci 2020;16:1753-66.

6. Nascimento IJB, Cacic N, Abdulazeem HM, Groote TC, Jayarajah U,
Weerasekara I, et al. Novel coronavirus infection (COVID-19) in humans: A scoping review and meta-analysis. J Clin Med 2020;9:941.

7. Tosepu R, Gunawan J, Effendy DS, Ahmad LO, Lestari H, Bahar H, et al. Correlation between weather and Covid-19 pandemic in Jakarta Indonesia. Sci Total Environ 2020;725:138436.

8. Buonsenso D, Piano A, Raffaelli F, Bonadia N, Donati KD, Franceschi F. Point of care lung ultrasound findings in novel coronavirus disease-19 pnemoniae: A case report and potential applications during COVID-19 outbreak. Eur Rev Med Pharmacol Sci 2020;24:2776-80.

9. Tan W, Aboudlhosn J. The cardiovascular burden of coronavirus disease 2019 (COVID-19) with a focus on congenital heart disease. Int J Cardiol 2020;309:70-7.

10. Kannan S, Ali PS, Sheeeza A, Hemalatha K. COVID-19 (novel coronavirus 2019)-recent trends. Eur Rev Med Pharmacol Sci 2020;24:2006-11.

11. Adhikari SP, Meng S, Wu YJ, Mao YP, Ye RX, Wang QZ, et al. Epidemiology, causes, clinical manifestation and diagnosis, prevention and control of coronavirus disease (COVID-19) during the early outbreak period: A scoping review. Infect Dis Poverty 2020;9:29.

12. Han R, Huang L, Jiang H, Dong J, Peng H, Zhang D. Early clinical and CT manifestations of coronavirus disease 2019 (COVID-19) pneumonia. Am J Roentgenol 2020;215:1-6.

13. Wei J, Xu H, Xiong J, Shen Q, Fan B, Ye C, et al. 2019 novel coronavirus (COVID-19) pneumonia: Serial computed tomography findings. Korean J Radiol 2020;21:501-4.

14. Cheng SC, Chang YC, Chiang YL, Chien YC, Cheng M, Yang CH, et al. First case of coronavirus disease 2019 (COVID-19) pneumonia in Taiwan. J Formos Med Assoc 2020;119:747-51.

15. Available from: https://www.who.int/news-room/fact-sheets/detail/ dengue-and-severe-dengue. [Last accessed on 2020 Mar 26].

16. Kalayanarooj S. Clinical manifestations and management of Dengue/ DHF/DSS. Trop Med Health 2011;39:83-7.

17. Guzman MG, Kouri G. Dengue diagnosis, advances and challenges. Int J Infect Dis 2004;8:69-80. 